\title{
Monocyte human leukocyte antigen-DR but not $\beta$-D-glucan may help early diagnosing invasive Candida infection in critically ill patients
}

Boris Jung ${ }^{1,2}$, Clément Le Bihan ${ }^{3,6}$, Pierre Portales ${ }^{4}$, Nathalie Bourgeois ${ }^{5}$, Thierry Vincent ${ }^{4}$, Laurence Lachaud ${ }^{5}$, Gerald Chanques ${ }^{2,6}$, Matthieu Conseil ${ }^{6}$, Philippe Corne ${ }^{1}$, Pablo Massanet ${ }^{7}$, Jean François Timsit $^{8}$ and Samir Jaber ${ }^{2,6^{*}}$

\begin{abstract}
Background: Precision medicine risk stratification is desperately needed to both avoid systemic antifungals treatment delay and over prescription in the critically ill with risk factors. The aim of the present study was to explore the combination of host immunoparalysis biomarker (monocyte human leukocyte antigen-DR expression (mHLA-DR)) and Candida sp wall biomarker $\beta$-D-glucan in risk stratifying patients for secondary invasive Candida infection (IC).

Methods: Prospective observational study. Two intensive care units (ICU). All consecutive non-immunocompromised septic shock patients. Serial blood samples $(n=286)$ were collected at day 0,2 and 7 and $\mathrm{mHLA}$-DR and $\beta$-D-glucan were then retrospectively assayed after discharge. Secondary invasive Candida sp infection occurrence was then followed at clinicians' discretion.

Results: Fifty patients were included, 42 (84\%) had a Candida score equal or greater than 3 and 10 patients developed a secondary invasive Candida sp infection. ICU admission mHLA-DR expression and $\beta$-D-glucan (BDG) failed to predict secondary invasive Candida sp infection. Time-dependent cause-specific hazard ratio of IC was 6.56 [1.24-34.61] for mHLA-DR<5000 Ab/c and 5.25 [0.47-58.9] for BDG $>350 \mathrm{pg} / \mathrm{mL}$. Predictive negative value of mHLA$\mathrm{DR}>5000 \mathrm{Ab} / \mathrm{c}$ and $\mathrm{BDG}>350 \mathrm{pg} / \mathrm{mL}$ combination at day 7 was $81 \%$ [95\% $\mathrm{Cl} 70-92]$.
\end{abstract}

Conclusions: This study suggests that mHLA-DR may help predicting IC in high-risk patients with septic shock. The added value of BDG and other fungal tests should be regarded according to the host immune function markers.

Keywords: Beta D-glucan, mHLA-DR, Candidiasis, Septic shock

\section{Background}

A keystone of sepsis is its association with systemic inflammation and immune-mediated damage [1]. However, it has been reported that along with systemic

\footnotetext{
*Correspondence: s-jaber@chu-montpellier.fr

${ }^{6}$ Saint Eloi Department of Anesthesiology and Critical Care Medicine, Montpellier University and Montpellier University Health Care Center, 34295 Montpellier, France

Full list of author information is available at the end of the article
}

inflammation comes a simultaneous anti-inflammatory response, mostly represented by a decrease in monocyte human leukocyte antigen-DR (mHLA-DR) expression, $\mathrm{T}$ cell exhaustion and impaired ability of proinflammatory response all of them leading to post-aggression host immunoparalysis [2, 3], a condition associated with both hospital acquired infections and mortality [4]. The majority of hospital acquired infections are represented by bacterial infections, but a proportion of the critically ill patients will develop hospital acquired invasive 
Candida infection (IC). IC incidence is increasing nowadays [5] and is associated with an ICU mortality rate up to 50\% [5-8]. Current pathogen-associated tools to help diagnose IC unfortunately either lack of sensitivity (e.g. cultures from sterile sites) or of specificity (clinical prediction scores, molecular biology, $\beta$-D-glucan wall biomarker detection) especially in the critically ill population $[6,9,10]$. The major diagnostic benefit of the recent $\beta$-D-glucan might be to help rule out IC as its negative predictive value has been reported to be about $90 \%$ [11]. Because delaying antifungal therapy initiation is a major determinant of clinical outcome $[12,13]$, intensivists desperately need better tools and/or bundles in the era of precision medicine to better screen patients at risk so their outcome can be improved antifungals over prescription being avoided [14].

The aim of the present study was to assess whether the combination of a host immunoparalysis biomarker (mHLA-DR) and a pathogen-associated biomarker ( $\beta$-Dglucan) would help stratifying critically ill patients with septic shock at risk to develop secondary IC.

\section{Methods}

\section{Study setting and patients}

This prospective observational study (ClinicalTrials.gov identifier: NCT03136081) was performed in two adult ICUs of a University hospital from June 2014 to May 2015. The study was approved by the ethic committee (Comité de Protection des Personnes Sud-Mediterranée III, 2014-A00500-47) and followed the STARD guidelines [15]. In accordance with French law, informed consent was obtained by the patient or his/her next of kin. Were included adult patients admitted to the 2 participating ICUs with non-fungal septic shock or adult patients who developed septic shock during the ICU stay taking into account logistical issues (research support to optimize patients screening, preanalytic issues during the week ends, assays availability, restricted funding). Noninclusion criteria were neutropenia (defined as a total leukocytes count $<500 / \mathrm{mm}^{3}$ ), immunosuppressive therapy, cancer-related chemotherapy in the last year, history of bone marrow or solid-organ transplantation. The patients were then split into two groups (IC and No-IC, $\mathrm{NIC}$ ) according to the occurrence of IC during the ICU stay.

\section{Definitions}

Septic shock was defined by evidence of infection and a systemic response to infection, in addition to a systolic blood pressure of $<90 \mathrm{mmHg}$, despite adequate fluid replacement, and a need for vasopressors for at least $1 \mathrm{~h}$, according to the American College of Chest Physicians/ Society of Critical Care Medicine Consensus Conference
Committee criteria [16]. The diagnosis of IC was made based on the revised consensus definitions of invasive fungal infections developed by the European Organization for Research and Treatment of Cancer/Invasive Fungal Infections Cooperative Group and the National Institute of Allergy and Infectious Disease Mycoses Study Group [17]. IC was defined by culture positives for Candida spp. from blood, per-operative peritoneal fluid or another sterile site. NIC was defined by the absence of proved IC. The IC follow-up was not standardized and let at the discretion of the clinicians.

\section{Baseline assessment and clinical data collection}

Clinical data were recorded at ICU admission: demographic characteristics, severity of underlying medical condition according to Simplified Acute Physiology Score II (SAPS II) [18], Sepsis-related Organ Failure Assessment (SOFA) score [19], the presence of comorbidities, reason for admission to the ICU and cause of septic shock. During the ICU stay, the following data were collected at days 0, 2 and 7; SOFA score, length of stay, duration of mechanical ventilation, need for vasopressor and survival at ICU discharge. Antibacterial and antifungal drugs were given according to the recommendation applied in a same way in both ICUs [20].

\section{Immunological data}

EDTA-anti-coagulated tubes were collected on each visit day (days 0, 2 and 7) for blood cell count, lymphocyte phenotype, CD4 T-cell, CD8 T-cell count and mHLADR. Circulating mHLA-DR expression was assessed by flow cytometry (NAVIOS ${ }^{\circledR}$; Beckman-Coulter) in accordance with the standardized recommendation [21, 22]. Monocytes were characterized on the basis of their CD14 expression. Results were expressed as the number of anti-HLA-DR antibodies per cell $(\mathrm{AB} / \mathrm{c})$. Clinicians were blinded for the immunological data results.

\section{Mycological data}

Candida colonization was screened at days 0 and 7 in at least 3 sites from urine, gastric aspiration, tracheal aspiration and cutaneous swab. Candida Score [23] was calculated for each visit day. Colonization was defined when one nonsterile sample site was positive for Candida sp. Culture positive for IV catheter without positive blood culture was deemed to be a colonization. Multifocal colonization was defined when more than one non sterile sample site was positive for Candida sp. Standardized procedures for in vitro identification of microorganism were used according to the usual procedures of the local mycology laboratory. Clinicians were blinded for the mycological data results. 


\section{Mycological biomarkers}

B-D-Glucan (BDG) was obtained on days 0,2 and 7. Blood samples $(15 \mathrm{~mL})$ were centrifuged, separated into aliquots, and stored at $-80{ }^{\circ} \mathrm{C}$ until analysis performed at the end of the study. The BDG assay (Fungitell ${ }^{\circledR}$, Associates of Cap Cod Inc., Easy Falmouth, MA, USA) was performed according to the manufacturer's recommendations. The cutoff value was set according to the company recommendations at $80 \mathrm{pg} / \mathrm{mL}[24,25]$. None of the results was available to the physician in charge.

\section{Endpoints}

The primary endpoint was the comparison of the kinetics during the first week after septic shock of mHLADR alone and in combination with BDG in IC and NIC patients.

\section{Statistical analysis}

Data are expressed as mean \pm SD or SEM for normally distributed data, and median with $95 \%$ confidence index (95\%CI) for non-normally distributed data. Comparisons and biomarkers kinetics between IC and NIC patients were made at day 0,2 and 7 . Continuous variables were compared using Student's t test for normally distributed variables and the Mann-Whitney rank-sum test for non-normally distributed variables. The Chi-square test or the Fisher exact test was used to compare categorical variables.

A cause-specific hazard model was built to assess the association of candida-related and immunologicals variables on the probability of death in the ICU or invasive Candida infection [26]. In this model, the occurrence of IC was the variable of interest, while death was considered as a competing event. Being discharged alive from the ICU was considered as a censored variable. Considering the low occurrence of candida infection only univariate analysis was performed. Candida variables and impaired immune function variables were fitted as timedependent covariables. The direct effect on the risk of IC was estimated by cause-specific hazard ratio (csHR).

Analysis of sensitivity, specificity, positive predictive value and negative predictive value was calculated for mycological and immunological markers separately and in association. For each marker, value over/ under the threshold was only considered if before an event (IC, death or ICU discharge). Delay of infection was estimated by the Kaplan-Meier method and compared between high- and low-risk patients (according to mHLA-DR and BDG values) with the log-rank test. A Monte Carlo simulation (considering the covariance between the two slopes) was also performed in order to assess the potentially best ROC curve. Expecting a
$20 \%$ incidence of Candida sp positive samples following septic shock, a drop of 50\% in mHLA-DR in the IC patients by day 7 and no significant difference between day 0 and day 7 in NIC patients, we estimated that 50 patients with septic shock would be needed assuming a bilateral test, an alpha risk of 0.05 and a power of 0.8 . A P value of less than 0.05 was taken as the significance level. We used SAS 9.4 (Sas Institute, NC, USA), R 3.0.2 (Vienna, Austria) and GraphPad Prism 6 for all the statistical analyses.

\section{Results}

Because of pre-analytic logistical issues, funding availability to facilitate screening and enrollment and logistical limitations in the assays availability, 50 patients met the inclusion criteria and were enrolled (Fig. 1). The baseline characteristics and outcome are shown in Table 1.

Forty-three patients were followed until day 2, 26 patients until day 7. Ten patients developed an IC during follow-up. The median time from septic shock to IC was 11 days (IQR 4.25-12.25). A cancer was present in $14 / 50$ patients $(28 \%)$ and was more frequent in IC compared to NIC patients ( $70 \%$ vs. $17.5 \%, p=0.001)$. There was no statistical difference in other baseline characteristics, ICU length of stay, mechanical ventilation and overall mortality between IC and NIC.

Peritonitis $(22 / 50,44 \%)$ and pneumonia $(11 / 50,22 \%)$ were the main sites of initial sepsis. Intra-abdominal candidiasis was the more frequent IC $(n=5)$, followed by candidemia $(n=4)$ and pleural infection $(n=1)$. A Candida Score $\geq 3$ was found in all IC patients before infection occurred and in $32(80 \%)$ NIC patients $(p=0.12)$. Antifungal therapy was used in 20 patients (40\%). Preemptive treatment was administered in 11 (27\%) NIC patients. Among the nine IC-treated patients, 5 (55\%) received initial preemptive therapy that was pursued once the IC was confirmed while 4 (45\%) received initial curative treatment. In one patient, the diagnosis of IC was made after ICU discharge and the treatment was not started. Echinocandins was the first agent in 45\% (9/20) and fluconazole in $55 \%(11 / 20)$.

A total of 286 immunological and mycological blood samples were collected. At day 0 and at day 2, mean mHLA-DR expression was not different between IC and NIC patients and above the threshold of $8000 \mathrm{AB} / \mathrm{c}$. At day 7, IC patients had a lower mHLA-DR expression than NIC patients $(3451 \pm 978 \mathrm{AB} / \mathrm{c}$ vs. $12,049 \pm 2044$ $\mathrm{AB} / \mathrm{c} ; \mathrm{p}=0.002$ ) (Fig. 2A). At day 0 , mean BDG was $97.5 \pm 35.6 \mathrm{pg} / \mathrm{mL}$ and $133.5 \pm 24.5 \mathrm{pg} / \mathrm{mL}$ for IC and NIC patients, respectively $(\mathrm{p}=0.38)$ (Fig. 2B).

In the cause-specific univariate model (Table 2), the time-dependent value of mHLA-DR $<8000 \mathrm{Ab} / \mathrm{c}$ was not significantly associated with IC (cs-HR 6.83 


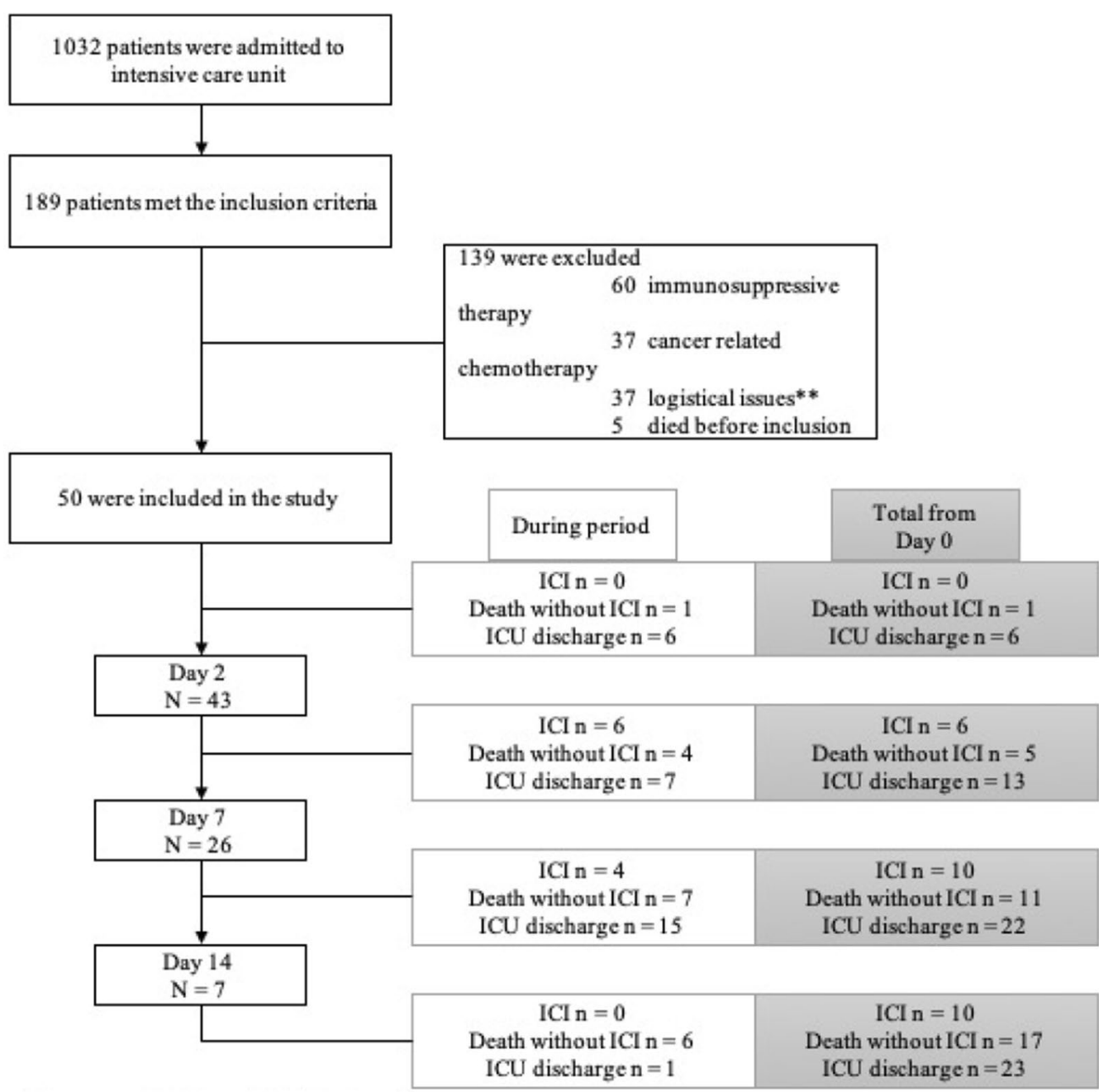

* preanalytic issues during the weck ends, assays availability, restricted funding

Fig. 1 Flowchart. /C Invasive Candida Infection, ICU intensive care unit

[0.81-57.53]). An mHLA-DR $<5000 \mathrm{Ab} / \mathrm{c}$ was associated with IC (cs-HR of 6.56 [1.24-34.61]) but not significantly associated with death (cs-HR 2.15 [0.43-10.68]).

No other time-dependent immunological marker was associated with an increased risk of IC or death. Mycological markers were not significantly associated with IC; BDG value $>80 \mathrm{pg} / \mathrm{mL}$ have cs-HR 0.63 [0.14-2.86] for IC and 2.07 [0.4-10.77] for death. History of cancer was associated with IC (cs-HR 7.17 [1.38-37.36]) without increased risk of death (cs-HR 1.38 [0.25-7.61]). Results for sensitivity, specificity, PPV and NPV are shown in Table 3. The combination of mHLA-DR $<5000 \mathrm{Ab} / \mathrm{c}$ and BDG $>80 \mathrm{pg} / \mathrm{mL}$ provides a PPV of $33.3 \%$ [95\% CI 6-60] and NPV of $84.2 \%$ [95\% CI 72-95]. Patients with mHLA-DR $<5000 \mathrm{Ab} / \mathrm{c}$ and $>5000 \mathrm{Ab} / \mathrm{c}$ at day 7 had a significantly different cumulative incidence of IC after day 7 with a log-rank test of 0.017 (Fig. 3A). No difference was found between patients with BDG $>80$ and $<80 \mathrm{pg} /$ $\mathrm{mL}$ (Fig. 3B). A composite score combining mHLA-DR and BDG was calculated with a logistic regression model. Based upon a Monte Carlo simulation of 10,000 patients the potentially better ROC curve was next realized. Area under the ROC curve was 0.65 .

\section{Discussion}

This prospective observational pilot study reports that a low value of mHLA-DR $(<5000 \mathrm{Ab} / \mathrm{c})$ after septic shock is associated with a higher risk of invasive Candida infection. Adding mycological markers such as BDG do not improve the predictive value in a high-risk population.

Both innate and adaptive immune response is of importance for controlling Candida colonization and infection. Blood monocytes and tissue macrophages 
Table 1 Characteristics and outcome of the study population

\begin{tabular}{|c|c|c|c|c|}
\hline & $\begin{array}{l}\text { Overall population } \\
(n=50)\end{array}$ & $\begin{array}{l}\text { No invasive candida } \\
\text { infection } \\
(n=40)\end{array}$ & $\begin{array}{l}\text { Invasive Candida infection } \\
(n=10)\end{array}$ & $p$-value \\
\hline Age & $66.4[60.5-71.3]$ & $66[57.8-70.3]$ & $69.5[60.7-74.5]$ & 0.343 \\
\hline Male & $34(68)$ & $27(67.5)$ & $7(70)$ & 0.880 \\
\hline SAPSII at admission & $50[43-62]$ & $48[42-58]$ & $58[47-66]$ & 0.143 \\
\hline SOFA score at admission & $10[7-12]$ & $9[7-12]$ & $11.5[7-13]$ & 0.528 \\
\hline \multicolumn{5}{|l|}{ Past medical history } \\
\hline Diabetes & $15(30)$ & $12(30)$ & $3(30)$ & 1.000 \\
\hline NYHA III-IV heart insufficiency & $8(16.3)$ & $8(20.5)$ & $0(0)$ & 0.117 \\
\hline Chronic renal failure & $5(10)$ & $4(10)$ & $1(10)$ & 1.000 \\
\hline Cirrhosis & $15(30)$ & $13(32.5)$ & $2(20)$ & 0.440 \\
\hline COPD & $12(24)$ & $11(27.5)$ & $1(10)$ & 0.246 \\
\hline Cancer & $14(28)$ & $7(17.5)$ & $7(70)$ & 0.001 \\
\hline \multicolumn{5}{|l|}{ Site of initial bacterial infection } \\
\hline Community-acquired pneumonia & $5(10)$ & $5(12.5)$ & $0(0)$ & 0.239 \\
\hline Health-care associated pneumonia & $6(12)$ & $4(10)$ & $2(20)$ & 0.384 \\
\hline Intra-abdominal infection & $17(34)$ & $11(27.5)$ & $6(60)$ & 0.052 \\
\hline Biliary tract infection & $5(10)$ & $4(10)$ & $1(10)$ & 1.000 \\
\hline Urinary tract infection & $2(4)$ & $2(5)$ & $0(0)$ & 0.470 \\
\hline Other infections & $9(18)$ & $8(20)$ & $1(10)$ & 0.915 \\
\hline \multicolumn{5}{|c|}{ Risk factors for Candida infection at inclusion } \\
\hline Candida colonization & $34(68)$ & $27(67.5)$ & $7(70)$ & 0.880 \\
\hline Multifocal Candida colonization & $32(64)$ & $24(60)$ & $8(80)$ & 0.239 \\
\hline Candida score & $4[3,4]$ & $3[3,4]$ & $4[4,5]$ & 0.071 \\
\hline Parenteral nutrition & $20(40)$ & $15(37.5)$ & $5(50)$ & 0.470 \\
\hline Surgery & $27(54)$ & $19(47.5)$ & $8(80)$ & 0.065 \\
\hline Abdominal surgery & $23(46)$ & $15(37.5)$ & $8(80)$ & 0.016 \\
\hline Broad-spectrum antibiotherapy & $50(100)$ & $40(100)$ & $10(100)$ & 1 \\
\hline \multicolumn{5}{|c|}{ Immunologicals and mycological parameters at inclusion } \\
\hline Total lymphocytes & 613 [349-992] & $620[391-1000]$ & $546[289-731]$ & 0.434 \\
\hline CD8+T cells & $73[51-184]$ & $71[47-167]$ & 124 [59-209] & 0.343 \\
\hline CD4+T cells & 279 [134-409] & $279[146-467]$ & $245[93-373]$ & 0.493 \\
\hline NK cells & $64[29-106]$ & $65[30-118]$ & $42[29-66]$ & 0.331 \\
\hline mHLA-DR & $9477[3605-15513]$ & 9426 [3978-15668] & $12,387[3592-13180]$ & 0.888 \\
\hline Beta-D-glucan & $73[22-145]$ & $76[16-181]$ & $62[34-107]$ & 0.872 \\
\hline \multicolumn{5}{|l|}{ Outcome and treatments } \\
\hline Antifungal therapy at inclusion & $20(40)$ & $11(27.5)$ & $9(90)$ & $<0.001$ \\
\hline Mechanical ventilation, days & $3[1-10]$ & $3[1-6.5]$ & $9[2-22]$ & 0.067 \\
\hline Vasopressors, days & $2.5[2-6]$ & $2.5[2-4.5]$ & $4[2-8]$ & 0.458 \\
\hline ICU length of stay & $7[4-14.5]$ & $7[4-14]$ & $9.5[3-22]$ & 0.596 \\
\hline Day in ICU before inclusion & $2[1,2]$ & $2[1,2]$ & $2[2-2]$ & 0.616 \\
\hline Death & $17(34)$ & $12(30)$ & $5(50)$ & 0.232 \\
\hline
\end{tabular}

Categorical data are expressed as number and percentage. Continuous data are expressed as median and quartiles. Comparisons were made between patients with invasive Candida infection and without invasive Candida infection

SAPS Simplified Acute Physiology Score, SOFA Sequential Organ Failure Assessment, NYHA New York Heart Association, COPD chronic obstructive pulmonary disease, mHLA-DR monocytic human leucocyte antigen DR, ICU intensive care unit

recognize pathogen-associated molecular patterns like fungal cell wall component. Antigen-presentation and subsequent cytokine secretion lead to T-helper lymphocyte activation and secondary adaptive immune response [27]. The expression of cell surface marker such as monocyte human leukocyte antigen-DR is 


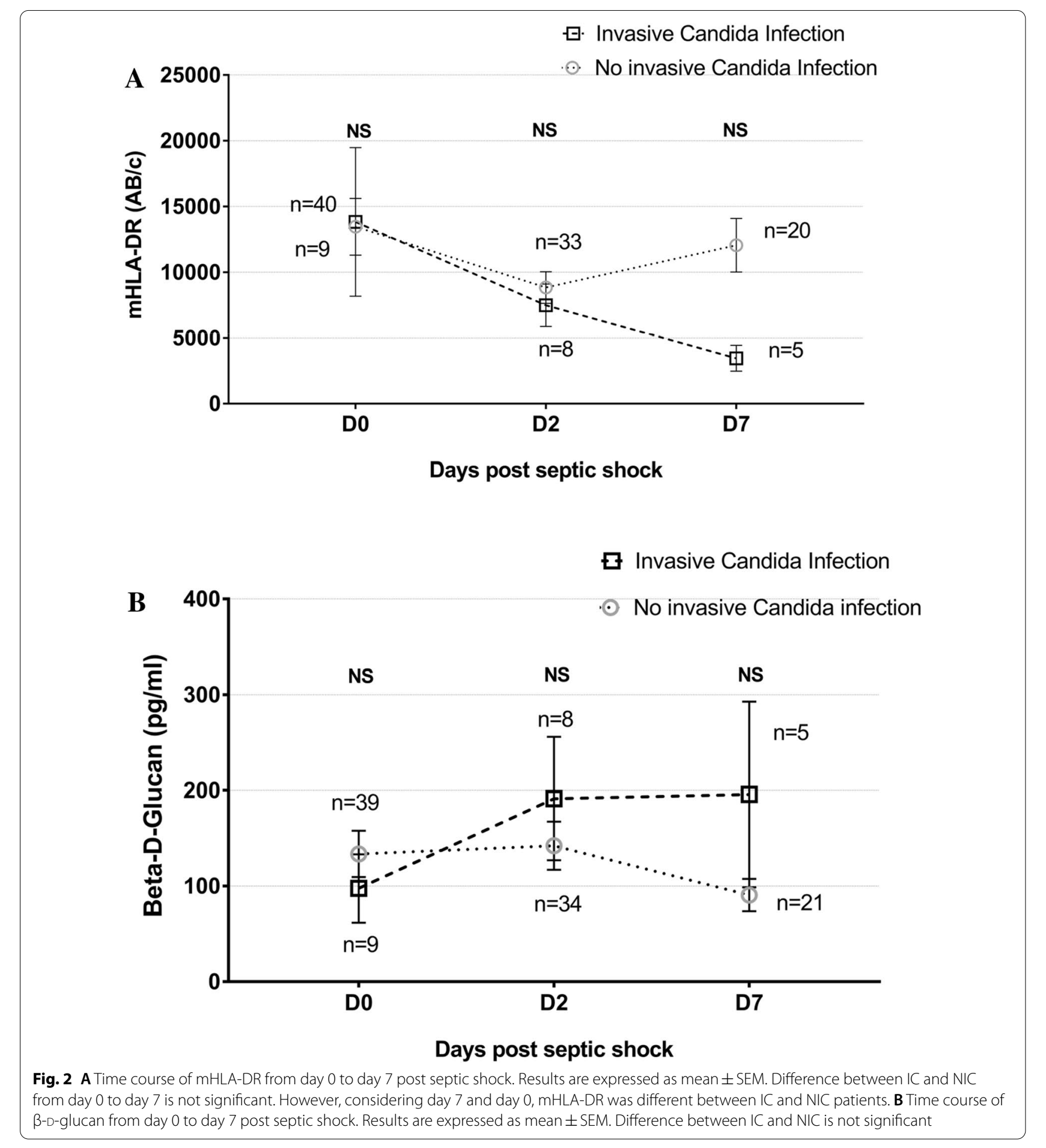

regulated by multiple pro and anti-inflammatory mediators [4] and mHLA-DR level of expression reflects activation of monocytes and immune function. Thereby, low mHLA-DR expression has been described as a robust marker of immune dysfunction [28] and outcome following septic shock $[4,29,30]$. Furthermore, the expression of mHLA-DR lower than $8000 \mathrm{AB} / \mathrm{c}$ has been described to increase the risk of hospital acquired infection following septic shock or multiple trauma in the critically ill $[21,22,31,32]$. In this study, mHLA-DR value $<8000 \mathrm{Ab} / \mathrm{c}$ was neither associated with $\mathrm{IC}$ nor death. Monocytic HLA-DR value $<5000 \mathrm{Ab} / \mathrm{c}$ was yet 
Table 2 Univariate cause-specific hazard ratio of invasive candida infection (competing risks: death, censored: alive discharge from $\mathrm{ICU})$

\begin{tabular}{|c|c|c|c|c|}
\hline & \multicolumn{2}{|c|}{ Cause-specific HR of invasive Candida infection } & \multicolumn{2}{|c|}{ Cause-specific HR of death } \\
\hline & $\mathrm{Cs}-\mathrm{HR}$ & $95 \% \mathrm{Cl}$ & Cs-HR & $95 \% \mathrm{Cl}$ \\
\hline Past history of cancer & 7.17 & {$[1.38-37.36]$} & 1.38 & {$[0.25-7.61]$} \\
\hline SAPS II (time-dependent) & 1.06 & {$[1.01-1.11]$} & 1.01 & {$[0.96-1.07]$} \\
\hline SOFA score (time-dependent) & 1.33 & {$[1.08-1.62]$} & 1.5 & {$[1.06-2.13]$} \\
\hline \multicolumn{5}{|l|}{ Immunological markers (time-dependent) } \\
\hline Total lymphocytes $<1100 / \mathrm{mm}^{3}$ & 1.24 & {$[0.15-10.29]$} & 1.04 & {$[0.12-8.96]$} \\
\hline Total lymphocytes $<500 / \mathrm{mm}^{3}$ & 3.83 & [0.74-19.81] & 1.49 & {$[0.3-7.4]$} \\
\hline CD4+ T cells $<200 / \mathrm{mm}^{3}$ & 4.49 & {$[0.87-23.23]$} & 3.6 & {$[0.66-19.67]$} \\
\hline CD8+T cells $<80 / \mathrm{mm}^{3}$ & 0.74 & {$[0.16-3.31]$} & 6.56 & {$[0.79-54.55]$} \\
\hline NK cells $<60 / \mathrm{mm}^{3}$ & 1.24 & {$[0.23-6.7]$} & 0.52 & {$[0.11-2.44]$} \\
\hline mHLA-DR $<5000 \mathrm{Ab} /$ cells & 6.56 & {$[1.24-34.61]$} & 2.15 & {$[0.43-10.68]$} \\
\hline mHLA-DR $<8000$ Ab/cells & 6.83 & {$[0.81-57.53]$} & 4.42 & {$[0.52-37.95]$} \\
\hline \multicolumn{5}{|l|}{ Fungals markers (time-dependent) } \\
\hline Empiric antifungal therapy & 1.15 & {$[0.25-5.22]$} & 0.31 & {$[0.04-2.56]$} \\
\hline Beta-D-glucan $>80$ pg/mL & 0.63 & {$[0.14-2.86]$} & 2.07 & {$[0.4-10.77]$} \\
\hline Candida score (total score) & 2.09 & {$[0.74-5.92]$} & 0.43 & {$[0.19-0.96]$} \\
\hline Number of Candida colonization sites & 1.17 & {$[0.59-2.32]$} & 1.52 & {$[0.68-3.37]$} \\
\hline Colonization index $>0.5$ & 4.1 & {$[0.38-44.5]$} & 2.91 & {$[0.23-36.23]$} \\
\hline
\end{tabular}

Evaluation of time-dependent mycological and immunological markers after septic shock and inclusion (from day 2 to day 14)

SAPS Simplified Acute Physiology Score, SOFA Sequential Organ Failure Assessment, mHLA-DR monocytic human leucocyte antigen DR

Table 3 Predictive value of fungal and immunological markers

\begin{tabular}{|c|c|c|c|c|c|c|c|c|}
\hline \multirow[b]{2}{*}{ Past history of cancer } & \multicolumn{2}{|c|}{$\begin{array}{l}\text { Sensitivity } \\
(95 \% \mathrm{CI})\end{array}$} & \multicolumn{2}{|c|}{$\begin{array}{l}\text { Specificity } \\
(95 \% \mathrm{Cl})\end{array}$} & \multicolumn{2}{|c|}{$\begin{array}{l}\text { PPV } \\
(95 \% \mathrm{CI})\end{array}$} & \multicolumn{2}{|c|}{$\begin{array}{l}\text { NPV } \\
(95 \% \mathrm{CI})\end{array}$} \\
\hline & 70 & {$[41-98]$} & 82.5 & [70-94] & 50.0 & [23-76] & 91.7 & [82-100] \\
\hline $\mathrm{BDG}>80$ & 70 & [41-98] & 42.5 & {$[27-57]$} & 23.3 & {$[8-38]$} & 85.0 & [69-100] \\
\hline$m H L A-D R<5000$ & 60 & [29-90] & 57.5 & [42-72] & 26.1 & {$[8-44]$} & 85.2 & [71-98] \\
\hline Total lymphocytes $<500$ & 80 & {$[55-100]$} & 45 & [29-60] & 26.7 & [10-42] & 90.0 & [76-100] \\
\hline CD4+T cells $<200$ & 80 & {$[55-100]$} & 60 & {$[44-75]$} & 33.3 & {$[14-52]$} & 92.3 & [82-100] \\
\hline \multicolumn{9}{|l|}{ Association of markers } \\
\hline mHLA-DR $<5000$ and BDG $>80$ & 40 & {$[9-70]$} & 80 & [67-92] & 33.3 & {$[6-60]$} & 84.2 & [72-95] \\
\hline Total lymphocytes $<500$ and BDG $>80$ & 70 & {$[41-98]$} & 62.5 & {$[47-77]$} & 31.8 & [12-51] & 89.3 & [77-100] \\
\hline CD4+T cells $<200 / \mathrm{mm}^{3}$ and BDG $>80$ & 70 & [41-98] & 70 & [55-84] & 36.8 & [15-58] & 90.3 & [79-100] \\
\hline Past history of cancer and mHLA-DR $<5000$ & 50 & [19-81] & 90 & [80-99] & 55.6 & [23-88] & 87.8 & [77-97] \\
\hline
\end{tabular}

mHLA-DR: monocyte human leukocyte antigen-DR (AB/c); BDG: $\beta$-d-glucan (pg/mL); PPV: positive predictive value; NVP: negative predictive value. Lymphocytes, CD4+ T cell, CD8+T cell $\left(/ \mathrm{mm}^{3}\right)$

associated with IC. Our population is mainly patients with sepsis related to peritonitis. Leijte et al. found median mHLA-DR over $6000 \mathrm{Ab} / \mathrm{c}$ in bacterial peritonitis [33]. Invasive candida infection commonly appears in highly immunosuppressed patients and lower value of mHLA-DR could be associated with higher risk of IC. Continuing or declining immune deficiency is associated with an increased mortality [33]. Similarly, our results suggest an increased probability of IC when
mHLA-DR remains $<5000 \mathrm{Ab} / \mathrm{c}$ after day 7 of septic shock.

We further explored whether Candida colonization and a fungal biomarker, BDG, could be of interest. Colonization and prediction scores have been developed to identify ICU patients at high risk of IC. In our study, colonization and Candida Score $(\geq 3)$ were positive in all IC 

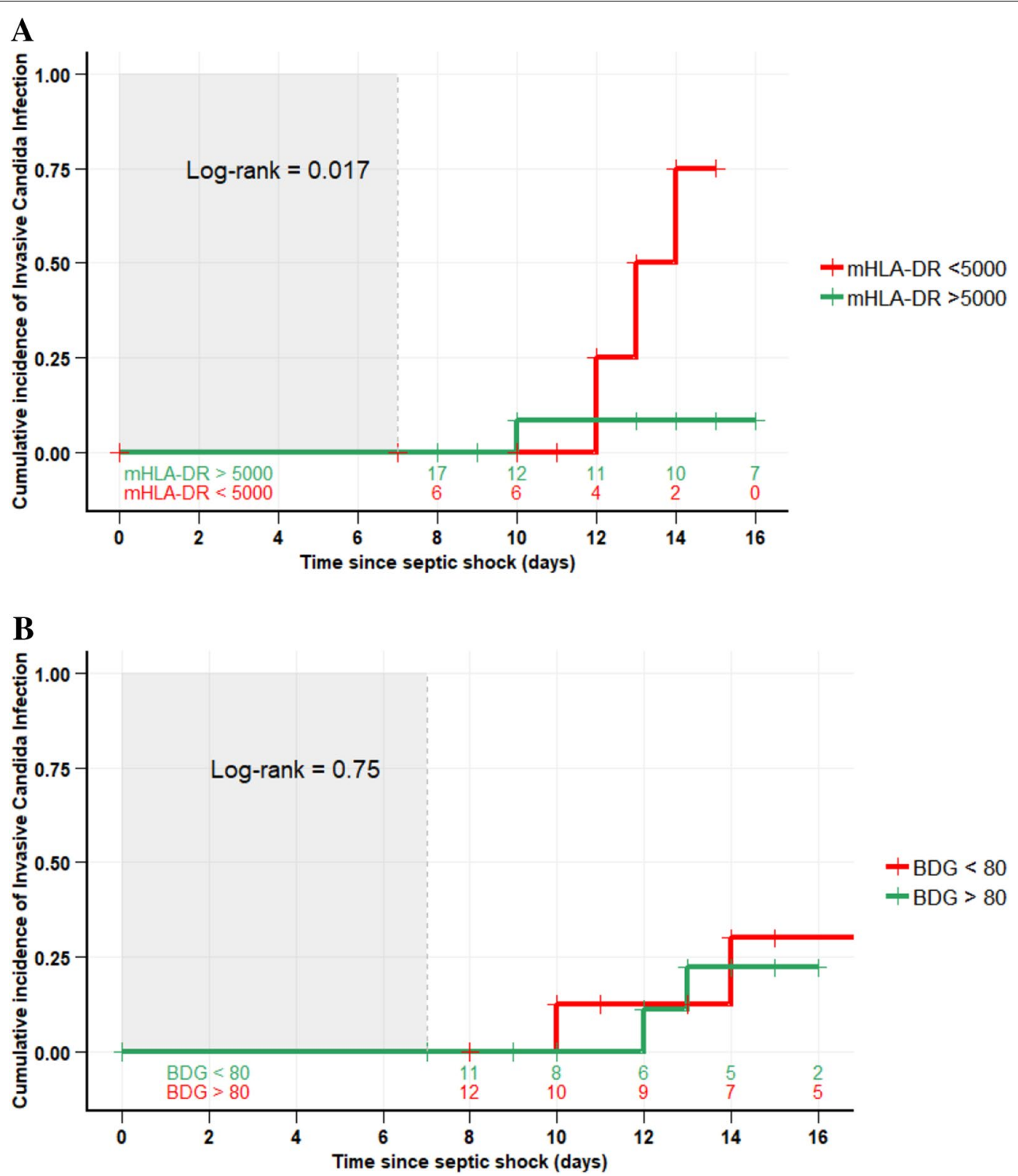

Fig. 3 A Probability of Invasive Candida Infection after day 7 according to Day 7 mHLA-DR (Ab/cell). B. Probability of Invasive Candida Infection after day 7 according to day $7 \beta$-D-glucan $(\mathrm{pg} / \mathrm{mL})$

patients and $80 \%$ of NIC patients, consistent with the low positive predictive value reported elsewhere [23, 34-36].

Colonization-driven antifungal treatment exposes to unnecessary antifungal treatment and its consequence on antifungal resistances and ecology [37-39]. In this regard, fungal biomarkers such as BDG have received increasing attention. Recent studies have evaluated the BDG performance to predict IC and have reported high sensitivity and specificity $[40,41]$. Others have reported mitigated results with sensitivity ranging from 40 to $100 \%$ [42-45]. Because of studies reporting high negative predictive value, BDG has been used either to rule out IC or to discontinue antifungal therapy as a part of antifungal stewardship [46-48]. In our study, the low negative predictive value and specificity of BDG suggests that BDG could not be used to rule IC out (Table 2). Furthermore, BDG could not be used to predict IC in the present study which is accordance with the recent study by Angebault et al. who reported a BDG sensitivity of $64 \%$ in candidemia [49]. This is also in line with studies that have shown that BDG driven therapy was not associated with outcome improvement $[50,51]$. 
When the combination of both host response (mHLA$\mathrm{DR})$ and fungal biomarker (BDG) was evaluated, the positive and negative value was not improved compared to mHLA-DR alone. Indeed, BDG predictive value may be decreased in high-risk population (Candida score 3 in $84 \%$ of patients). Past history of cancer was associated with an increased risk of IC. This result was previously described by Lortholary [52]. An increased expression of negative T-cell co-stimulatory molecule (PD1, CTLA4) was described in both cancer [53] and candida-related sepsis [54] revealing possible immunological similarities.

The present study has some major limits. First, this is a single institution study with a relatively small cohort and a limited number of patients at day 7 because of deaths or discharge from the ICU. Second, $27 \%$ of patients in NIC group have received pre-emptive treatment at inclusion or during the ICU stay limiting IC occurrence in some of them. Third, we could have also evaluated other fungal biomarkers such as mannan/antimannan, Candida albicans germ tube antibody or T2Candida Panel that have been associated with a high negative predictive value, but we lacked funding and did choose to focus on a pair of pathogen and host-related biomarkers.

\section{Conclusion}

This study suggests that a sepsis-induced immune dysfunction (mHLA-DR $<5000 \mathrm{Ab} / \mathrm{c}$ ) is associated with a higher risk of ICU acquired invasive candida infection in patient with septic shock. Combination with fungal biomarker (BDG) did not enhance the prediction value. Larger studies are needed before implementing these results in the routine care.

\section{Appendix 1}

\begin{tabular}{llll}
\hline Candida species & $\begin{array}{l}\text { Colonization at } \\
\text { inclusion } \\
(\boldsymbol{n}=\mathbf{3 4 / 5 0 )}\end{array}$ & $\begin{array}{l}\text { Colonization } \\
\text { anytime } \\
(\boldsymbol{n}=\mathbf{4 1 / 5 0 )}\end{array}$ & $\begin{array}{l}\text { Invasive } \\
\text { infection } \\
(\boldsymbol{n}=\mathbf{1 0 / 5 0 )}\end{array}$ \\
\hline $\begin{array}{l}\text { Colonization/infection } \\
\text { With only one specie }\end{array}$ & $22(65)$ & $25(60)$ & \\
With multiple species & $12(35)$ & $14(34)$ & \\
Candida albicans & $20(59)$ & $23(56)$ & $7(70)$ \\
Candida glabrata & $9(26)$ & $10(24)$ & $1(10)$ \\
Candida parapsilosis & $9(26)$ & $10(24)$ & $1(10)$ \\
Candida tropicalis & $4(12)$ & $4(10)$ & $1(10)$ \\
Other species & $10(29)$ & $12(29)$ & \\
\hline
\end{tabular}

\section{Abbreviations}

BDG: $\beta$-D-Glucan; CsHR: Cause-specific hazard ratio; IC: Invasive Candida infection; mHLA-DR: Monocyte human leukocyte antigen-DR; NIC: No invasive Candida infection; SAPSII: Simplified Acute Physiology Score II; SOFA: Sepsisrelated Organ Failure Assessment.

\section{Acknowledgements}

We thank Claudine Gniadek, Albert Prades, Cecile Spirito, Oceane Garnier, and Fabrice Galia for their assistance in collecting the clinical data. We also thank Michèle Lefebvre, research technician, for performing the BDG technique.

\section{Authors' contributions}

BJ, CLB and SJ had full access to all of the data in the study and take responsibility for the integrity of the data and the accuracy of the data analysis.

Concept and design: $\mathrm{BJ}, \mathrm{PM}, \mathrm{CLB}$ and $\mathrm{SJ}$. Acquisition, analysis or interpretation of data: BJ, CLB, PP, PM, PC, NB, JFT, SJ. Drafting of the manuscript: BJ, CLB, JFT, SJ. Critical revision of the manuscript for important intellectual content: $B J$, CLB, PC, JFT, SJ, LL, TV, MCO, GC. Statistical analysis: CLB, JFT. Obtained funding: BJ. Supervision: BJ, SJ. All authors read and approved the final manuscript.

\section{Funding}

The present study was funded by a Montpellier-Nîmes University Hospitals Young researchers Grant (UIC 9358, PI: BJ).

\section{Availability of data and materials}

The datasets used and analyzed during the current study are available from the corresponding author on reasonable request.

\section{Declarations}

Ethics approval and consent to participate

The study was approved by the ethic committee (Comité de Protection des Personnes Sud-Mediterranée III, 2014-A00500-47).

\section{Consent for publication}

Informed consent was obtained from all individual participants included in the study or their legally authorized representatives.

\section{Competing interests}

SJ declares consulting fees from Drager, Xenios and Fisher \& Paykel. BJ does not declare any conflicts of interests. GC declares speaker fees from Aspen medical and Orion pharma and consulting fees from Orion pharma. JFT declares speaker fees from Merck, Pfizer, Biomerieux; consulting fees from Pfizer, Gilead, Merck, Nabriva, Paratek, Medimune and research grants from $3 \mathrm{M}$, Merck, Pfizer. Other authors do not declare any conflicts of interests.

\section{Author details}

${ }^{1}$ Medical Intensive Care Unit, Montpellier University and Montpellier University Health Care Center, 34290 Montpellier, France. ${ }^{2}$ PhyMedExp Laboratory, Montpellier University, INSERM, CNRS, CHRU Montpellier, 34295 Montpellier, France. ${ }^{3}$ Département des Maladies Infectieuses et Tropicales, Montpellier University and Montpellier University Health Care Center, 34295 Montpellier, France. ${ }^{4}$ Immunology Department, Montpellier University and Montpellier University Health Care Center, 34295 Montpellier, France. ${ }^{5}$ Département de Parasitologie-Mycologie, Montpellier University and Montpellier University Health Care Center, UMR Mivegec, 34295 Montpellier, France. ${ }^{6}$ Saint Eloi Department of Anesthesiology and Critical Care Medicine, Montpellier University and Montpellier University Health Care Center, 34295 Montpellier, France.

${ }^{7}$ Department of Anesthesiology and Critical Care Medicine, Centre Hospitalier Universitaire Nîmes, 30000 Nîmes, France. ${ }^{8}$ APHP Hôpital Bichat-Claude Bernard, Paris-Diderot University, 75000 Paris, France.

Received: 23 February 2021 Accepted: 5 August 2021

Published online: 21 August 2021

\section{References}

1. Delano MJ, Ward PA. The immune system's role in sepsis progression, resolution, and long-term outcome. Immunol Rev. 2016;274:330-53. 
2. Hotchkiss RS, Monneret G, Payen D. Immunosuppression in sepsis: a novel understanding of the disorder and a new therapeutic approach. Lancet Infect Dis. 2013;13:260-8.

3. Asehnoune K, Roquilly A, Abraham E. Innate immune dysfunction in trauma patients: from pathophysiology to treatment. Anesthesiology. 2012;117:411-6.

4. Monneret G, Lepape A, Voirin N, Bohé J, Venet F, Debard A-L, et al. Persisting low monocyte human leukocyte antigen-DR expression predicts mortality in septic shock. Intensive Care Med. 2006;32:1175-83.

5. Lortholary O, Renaudat C, Sitbon K, Madec Y, Denoeud-Ndam L, Wolff $M$, et al. Worrisome trends in incidence and mortality of candidemia in intensive care units (Paris area, 2002-2010). Intensive Care Med. 2014:40:1303-12.

6. Kullberg BJ, Arendrup MC. Invasive Candidiasis. N Engl J Med. 2015;373:1445-56.

7. Puig-Asensio M, Pemán J, Zaragoza R, Garnacho-Montero J, MartínMazuelos E, Cuenca-Estrella M, et al. Impact of therapeutic strategies on the prognosis of candidemia in the ICU. Crit Care Med. 2014;42:1423-32.

8. Leroy O, Bailly S, Gangneux J-P, Mira J-P, Devos P, Dupont H, et al. Systemic antifungal therapy for proven or suspected invasive candidiasis: the AmarCAND 2 study. Ann Intensive Care. 2016;6:1.

9. Clancy CJ, Nguyen MH. Finding the "missing 50\%" of Invasive Candidiasis: how nonculture diagnostics will improve understanding of disease spectrum and transform patient care. Clin Infect Dis. 2013;56:1284-92.

10. Smith JA, Kauffman CA. Recognition and prevention of nosocomial invasive fungal infections in the intensive care unit. Crit Care Med. 2010;38:S380-387.

11. Lamoth F, Cruciani M, Mengoli C, Castagnola E, Lortholary O, Richardson $M$ et al. Glucan antigenemia assay for the diagnosis of invasive fungal infections in patients with hematological malignancies: a systematic review and meta-analysis of cohort studies from the Third European Conference on Infections in Leukemia (ECIL-3). Clin Infect Dis. 2012;54:633-43.

12. Puig-Asensio M, Pemán J, Zaragoza R, Garnacho-Montero J, MartínMazuelos E, Cuenca-Estrella M, et al. Impact of therapeutic strategies on the prognosis of Candidemia in the ICU*. Crit Care Med. 2014;42:1423-32.

13. Andes DR, Safdar N, Baddley JW, Playford G, Reboli AC, Rex JH, et al. Impact of treatment strategy on outcomes in patients with candidemia and other forms of invasive Candidiasis: a patient-level quantitative review of randomized trials. Clin Infect Dis. 2012;54:1110-22.

14. Bassetti M, Garnacho-Montero J, Calandra T, Kullberg B, Dimopoulos G, Azoulay $E$, et al. Intensive care medicine research agenda on invasive fungal infection in critically ill patients. Intensive Care Med. 2017:43:1225-38.

15. Cohen JF, Korevaar DA, Altman DG, Bruns DE, Gatsonis CA, Hooft L, et al. STARD 2015 guidelines for reporting diagnostic accuracy studies: explanation and elaboration. BMJ Open. 2016;6:e012799.

16. Bone RC, Balk RA, Cerra FB, Dellinger RP, Fein AM, Knaus WA, et al. Definitions for sepsis and organ failure and guidelines for the use of innovative therapies in sepsis. The ACCP/SCCM Consensus Conference Committee American College of Chest Physicians/Society of Critical Care Medicine. Chest. 1992;101:1644-55.

17. De Pauw B, Walsh TJ, Donnelly JP, Stevens DA, Edwards JE, Calandra T, et al. Revised definitions of invasive fungal disease from the European Organization for research and treatment of cancer/invasive fungal infections Cooperative Group and the National Institute of Allergy and Infectious Diseases Mycoses Study Group (EORTC/MSG) Consensus Group. Clin Infect Dis. 2008;46:1813-21.

18. Gall J-RL, Lemeshow S, Saulnier F. A new simplified acute physiology score (SAPS II) based on a European/North American multicenter study. JAMA. 1993;270:2957-63.

19. Vincent J-L, Rello J, Marshall J, Silva E, Anzueto A, Martin CD, et al. International study of the prevalence and outcomes of infection in intensive care units. JAMA. 2009;302:2323-9.

20. Cornely OA, Bassetti M, Calandra T, Garbino J, Kullberg BJ, Lortholary O, et al. ESCMID* quideline for the diagnosis and management of Candida diseases 2012: non-neutropenic adult patients: diagnosis and management of Candida diseases 2012. Clin Microbiol Infect. 2012;18:19-37.

21. Döcke W-D, Höflich C, Davis KA, Röttgers K, Meisel C, Kiefer P, et al. Monitoring temporary immunodepression by flow cytometric measurement of monocytic HLA-DR expression: a multicenter standardized study. Clin Chem. 2005;51:2341-7.
22. Cheron A, Floccard B, Allaouchiche B, Guignant C, Poitevin F, Malcus C, et al. Lack of recovery in monocyte human leukocyte antigen-DR expression is independently associated with the development of sepsis after major trauma. Crit Care. 2010;14:R208.

23. Leon C, Ruiz-Santana S, Saavedra P, Galvan B, Blanco A, Castro C, et al. Usefulness of the "Candida score" for discriminating between Candida colonization and invasive candidiasis in non-neutropenic critically ill patients: A prospective multicenter study. Crit Care Med. 2009;37:1624-33.

24. Held J, Kohlberger I, Rappold E, Busse Grawitz A, Häcker G. Comparison of (1->3)- $\beta$-D-glucan, mannan/anti-mannan antibodies, and Cand-Tec Candida antigen as serum biomarkers for candidemia. J Clin Microbiol. 2013:51:1158-64.

25. Ostrosky-Zeichner L, Shoham S, Vazquez J, Reboli A, Betts R, Barron MA, et al. MSG-01: a randomized, double-blind, placebo-controlled trial of Caspofungin prophylaxis followed by preemptive therapy for invasive Candidiasis in high-risk adults in the critical care setting. Clin Infect Dis. 2014;58:1219-26.

26. Lau B, Cole SR, Gange SJ. Competing risk regression models for epidemiologic data. Am J Epidemiol. 2009;170:244-56.

27. Romani L. Immunity to fungal infections. Nat Rev Immunol. 2011;11:275-88.

28. Monneret G, Venet F, Pachot A, Lepape A. Monitoring immune dysfunctions in the septic patient: a new skin for the old ceremony. Mol Med. 2008;14:64-78.

29. Landelle C, Lepape A, Voirin N, Tognet E, Venet F, Bohé J, et al. Low monocyte human leukocyte antigen-DR is independently associated with nosocomial infections after septic shock. Intensive Care Med. 2010;36:1859-66

30. Wu J-F, Ma J, Chen J, Ou-Yang B, Chen M-Y, Li L-F, et al. Changes of monocyte human leukocyte antigen-DR expression as a reliable predictor of mortality in severe sepsis. Crit Care. 2011;15:R220.

31. Meisel C, Schefold JC, Pschowski R, Baumann T, Hetzger K, Gregor J, et al. Granulocyte-macrophage colony-stimulating factor to reverse sepsisassociated immunosuppression: a double-blind, randomized, placebocontrolled multicenter trial. Am J Respir Crit Care Med. 2009;180:640-8.

32. Lukaszewicz A-C, Grienay M, Resche-Rigon M, Pirracchio R, Faivre V, Boval B, et al. Monocytic HLA-DR expression in intensive care patients: Interest for prognosis and secondary infection prediction*. Crit Care Med. 2009;37:2746-52

33. Leijte GP, Rimmelé T, Kox M, Bruse N, Monard C, Gossez M, et al. Monocytic HLA-DR expression kinetics in septic shock patients with different pathogens, sites of infection and adverse outcomes. Crit Care. 2020;24:110.

34. León C, Ruiz-Santana S, Saavedra P, Castro C, Úbeda A, Loza A, et al. Value of $\beta$-d-glucan and Candida albicans germ tube antibody for discriminating between Candida colonization and invasive candidiasis in patients with severe abdominal conditions. Intensive Care Med. 2012;38:1315-25.

35. Leroy G, Lambiotte F, Thévenin D, Lemaire C, Parmentier E, Devos P, et al. Evaluation of "Candida score" in critically ill patients: a prospective, multicenter, observational, cohort study. Ann Intensive Care. 2011;1:50.

36. Ostrosky-Zeichner L, Sable C, Sobel J, Alexander BD, Donowitz G, Kan V, et al. Multicenter retrospective development and validation of a clinical prediction rule for nosocomial invasive candidiasis in the intensive care setting. Eur J Clin Microbiol Infect Dis. 2007;26:271-6.

37. Shields RK, Nguyen MH, Clancy CJ. Clinical perspectives on echinocandin resistance among Candida species. Curr Opin Infect Dis. 2015;28:514-22.

38. Azoulay E, Dupont H, Tabah A, Lortholary O, Stahl J-P, Francais A, et al. Systemic antifungal therapy in critically ill patients without invasive fungal infection*. Crit Care Med. 2012;40(3):813-22.

39. Massanet $P$, Jung B, Molinari N, Villiet M, Moulaire V, Roch-Torreilles I, et al. Traitements antifongiques en réanimation au cours des infections fongiques invasives documentées ou suspectées. Ann Fr Anesth Réanimation. 2014;33:232-9.

40. Posteraro B, De Pascale G, Tumbarello M, Torelli R, Pennisi MA, Bello G, et al. Early diagnosis of candidemia in intensive care unit patients with sepsis: a prospective comparison of $(1 \rightarrow 3)-\beta-D-g l u c a n$ assay, Candida score, and colonization index. Crit Care. 2011;15:R249.

41. Tissot F, Lamoth F, Hauser PM, Orasch C, Flückiger U, Siegemund M, et al. $\beta$-Glucan antigenemia anticipates diagnosis of blood culture-negative intraabdominal candidiasis. Am J Respir Crit Care Med. 2013;188:1100-9. 
42. Theel ES, Doern CD. $\beta$-D-glucan testing is important for diagnosis of invasive fungal infections. J Clin Microbiol. 2013;51:3478-83.

43. Karageorgopoulos DE, Vouloumanou EK, Ntziora F, Michalopoulos A, Rafailidis PI, Falagas ME. $\beta$-D-glucan assay for the diagnosis of invasive fungal infections: a meta-analysis. Clin Infect Dis. 2011;52:750-70.

44. Koo S, Bryar JM, Page JH, Baden LR, Marty FM. Diagnostic performance of the $(1 \rightarrow 3)$ - $\beta$-d-glucan assay for invasive fungal disease. Clin Infect Dis. 2009;49:1650-9.

45. Ostrosky-Zeichner L, Alexander BD, Kett DH, Vazquez J, Pappas PG, Saeki F, et al. Multicenter clinical evaluation of the (1->3) beta-D-glucan assay as an aid to diagnosis of fungal infections in humans. Clin Infect Dis Off Publ Infect Dis Soc Am. 2005:41:654-9.

46. Ostrosky-Zeichner L, Kullberg BJ, Bow EJ, Hadley S, León C, Nucci M, et al. Early treatment of candidemia in adults: a review. Med Mycol. 2011;49:113-20

47. Nucci M, Nouér SA, Esteves P, Guimarães T, Breda G, de Miranda BG, et al. Discontinuation of empirical antifungal therapy in ICU patients using 1,3-ß-d-glucan. J Antimicrob Chemother. 2016;71:2628-33.

48. Bassetti M, Peghin M, Timsit J-F. The current treatment landscape: candidiasis. J Antimicrob Chemother. 2016:71:13-22.

49. Angebault C, Lanternier F, Dalle F, Schrimpf C, Roupie A-L, Dupuis A, et al. Prospective evaluation of serum $\beta$-glucan testing in patients with probable or proven fungal diseases. Open Forum Infect Dis. 2016;3:ofw128.
50. Posteraro B, Tumbarello M, De Pascale G, Liberto E Vallecoccia MS, De Carolis E, et al. (1,3)- $\beta$-d-Glucan-based antifungal treatment in critically ill adults at high risk of candidaemia: an observational study. J Antimicrob Chemother. 2016;71:2262-9.

51. Timsit J-F, Azoulay E, Schwebel C, Charles PE, Cornet M, Souweine B, et al. Empirical micafungin treatment and survival without invasive fungal infection in adults with ICU-acquired sepsis, Candida colonization, and multiple organ failure: The EMPIRICUS randomized clinical trial. JAMA. 2016:316:1555

52. Lortholary O, Renaudat C, Sitbon K, Desnos-Ollivier M, Bretagne S, Dromer $F$, et al. The risk and clinical outcome of candidemia depending on underlying malignancy. Intensive Care Med. 2017;43:652-62.

53. Brahmer JR, Tykodi SS, Chow LQM, Hwu W-J, Topalian SL, Hwu P, et al. Safety and activity of anti-PD-L1 antibody in patients with advanced cancer. N Engl J Med. 2012;366:2455-65.

54. Desai JV, van de Veerdonk FL, Lionakis MS. Understanding the role of host immune responses in invasive candidiasis. Intensive Care Med. 2018:44:1310-4.

\section{Publisher's Note}

Springer Nature remains neutral with regard to jurisdictional claims in published maps and institutional affiliations.

\section{Submit your manuscript to a SpringerOpen ${ }^{\circ}$ journal and benefit from:}

- Convenient online submission

$\checkmark$ Rigorous peer review

- Open access: articles freely available online

- High visibility within the field

- Retaining the copyright to your article

Submit your next manuscript at $\boldsymbol{\nabla}$ springeropen.com 